\title{
ESCOCIA: EL REFERÉNDUM \\ SOBRE LA INDEPENDENCIA Y LA PROPUESTA \\ DE REFORMA DE LA DEVOLUTION (*)
}

\author{
Scotland: the referendum on independence \\ and the proposed reform of the Devolution
}

\author{
ALBERTO LÓPEZ BASAGUREN
}

\section{RESUMEN}

Este trabajo tiene como objeto el referéndum sobre la independencia realizado en Escocia en septiembre de 2014. Analiza los resultados del referéndum, poniendo de relieve los aspectos más significativos, como, muy destacadamente, los desequilibrios en la distribución territorial del voto contrario a la independencia, así como por sexos y por grupos de edad. Indaga en las motivaciones del electorado a la luz de los argumentos utilizados y del desarrollo del debate sobre la independencia, durante el año que precedió a la votación. Finalmente, expone las propuestas realizadas por la Comisión Smith, creada inmediatamente después de la victoria del «no», en relación con la reforma de la Devolution (autonomía territorial) para la ampliación de los poderes del Parlamento escocés, y la inicial reacción del Parlamento escocés al proyecto legislativo presentado por el Gobierno británico para su aplicación.

PALABRAS CLAVE: Escocia; referéndum; independencia; Devolution (reforma); Comisión Smith.

(*) Universidad del País Vasco (UPV/EHU). Grupo de Investigación del Sistema Vasco IT743-13. Proyecto de Investigación DER 2013-47774-P, financiado por el Ministerio de Economía y Competitividad. Este trabajo es deudor de la estancia sabática en Clare Hall (College) de la Universidad de Cambridge (2011-12), así como de las estancias en las Universidades de Edimburgo y Dundee (2013); quiero expresar mi agradecimiento al profesor John BELL (Cambridge), al profesor Stephen TIERNEY y a la Dra. Elisenda CASAÑAS-ADAM (Edinburgh) y al profesor Alan PAGE (Dundee) por la ayuda prestada. Tuve la oportunidad de exponer estas cuestiones en los Seminarios de Sedano (Burgos) y Universidad Autónoma de Madrid (junio y octubre de 2013), dirigidos por el profesor Francisco RUBIO LLORENTE, a quien agradezco — así como a los profesores Juan J. SOLOZÁBAL, Manuel ARAGÓN y a todos quienes participaron en ellos- haber tenido la oportunidad de someterlo a debate en un ambiente académico tan riguroso en lo intelectual como cálido y acogedor en lo personal. Debo agradecer al Dr. Alan TRENCH - Constitution Unit, UCL — sus valiosas explicaciones sobre el sistema tributario británico. 


\section{ABSTRACT}

This work aims to analyse the referendum on independence held in Scotland in September 2014. It shows the results of the referendum, highlighting the most significant aspects, such as, in particular, the imbalances in the geographical distribution of the vote against independence, as well as by sex and age groups. It explores the motivations of the electorate in the light of the arguments used and the development of the debate on independence, during the year preceding the vote. Finally, it presents the proposals made by the Smith Commission, established immediately after the victory of the «no», in relation to the reform of Devolution (territorial autonomy) to increase the powers of Scotland, and the initial reaction of the Scottish Parliament regarding the bill presented by the British Government for the implementation of those proposals.

KEY WORDS: Scotland; referendum; independence; Devolution (amendment); Smith Commission.

I. INTRODUCCIÓN.-II. EL REFERÉNDUM SOBRE LA INDEPENDENCIA DE ESCOCIA: 1. Los resultados. 2. Los elementos del debate y las motivaciones del electorado.-III. EL COMPROMISO DE REFORMA DE LA DEVOLUTIONY LAS PROPUESTAS DE LA COMISIÓN SMITH.IV. CONCLUSIONES.-Bibliografía UTILIZADA.

\section{INTRODUCCIÓN}

El proceso político puesto en marcha por el SNP — Scottish National Party - a partir de su acceso al Gobierno escocés tras las elecciones de 2007 — con un gobierno minoritario - y, muy especialmente, a partir de la mayoría absoluta lograda en las elecciones de 2011, tenía un doble objetivo, de carácter complementario: la ampliación de la autonomía escocesa (1) y la realización de un referéndum sobre la independencia (2).

Todos los indicadores mostraban que el apoyo a la independencia era muy reducido (entre 28 por $100-30$ por 100 , en las mejores perspectivas), por lo que

(1) Sobre la autonomía escocesa, en castellano, es ineludible el trabajo de C. G. Esteban Campos, 2005. Sobre el desarrollo del proceso que lleva al referéndum, S. SÁNCHEZ FERRO, 2015: 111 y sigs.; sobre la Devolution, A. LÓPEZ BASAGUREN, 2014a: 150 y sigs.

(2) Sobre la reclamación de la independencia para Escocia y las cuestiones político-constitucionales que suscita, sigue siendo imprescindible el adelantado análisis de J. E. Murkens (2002). 
el objetivo fundamental de los nacionalistas escoceses era lo que se conoce como devo-max: la plena autonomía fiscal (3), cuya demanda no había sido satisfecha por la Scotland Act 2012, por la que se reformó la de 1998 (4), que había quedado superada incluso antes de su aplicación práctica (5). El referéndum sobre la independencia se presentaba como un instrumento político a largo plazo, de reforzamiento de las pretensiones últimas del nacionalismo, $y$, a corto plazo, como un reforzamiento disuasorio a favor de la ampliación de la autonomía.

Tras el rotundo triunfo electoral de 2011, el Gobierno del SNP, liderado por Alex Salmond, centró su estrategia en la realización de un referéndum que combinara las dos propuestas contenidas en su programa. El Gobierno británico aceptará el reto y su resultado será el Acuerdo de Edimburgo [Edinburgh Agreement], de 15 de octubre de 2012 (S. Tierney, 2013; E. Casanas-Adam, 2014; S. Sánchez Ferro, 2015). En el acuerdo se imponía el criterio de que el Parlamento escocés, de acuerdo a la Scotland Act, carecía de competencia para su convocatoria. Se trataba de controlar el riesgo de lo que en el RU se ha denominado «neverendum», el referéndum de nunca acabar. Suponía establecer un principio que impidiese que sucesivos Gobiernos escoceses pudiesen decidir por sí mismos la realización de nuevos referenda en el futuro, a su conveniencia política, sin ningún tipo de límite. Se trataba, además, de imponer el criterio del Gobierno británico de que el referéndum debía contener una sola pregunta «simple y

(3) En el Manifesto (programa) para las elecciones de 2011, la propuesta del SNP era nítida: la asunción por Escocia de la plena responsabilidad en materia financiera, de forma que las instituciones escocesas recaudasen la totalidad de los impuestos, transfiriendo al Gobierno británico la cantidad correspondiente a la contribución de Escocia a los servicios compartidos con el RU «tales como las pensiones, los asuntos exteriores y la defensa».

(4) En el documento Scotland's Future: Draft Referendum (Scotland) Bill Consultation Paper, de febrero de 2010, aunque se recordaba el apoyo del Gobierno escocés a algunas de las medidas propuestas, se afirmaba tajantemente que «the (Calman) Commission's proposals for financial accountability are seriously flawed and fall far short of the fiscal responsibilities which Scotland needs to become a more successful country» (par. 1.13, pág. 13).

(5) La entrada en vigor de las disposiciones más importantes —el tipo escocés sobre la Income Tax - estaba prevista para abril de 2016. El 1 de abril de 2015 han entrado en vigor los primeros impuestos escoceses —el Land and Buildings Transaction Tax y el Scottish Landfill Tax, que sustituyen al Stamp Duty Land Tax y al UK Landfill Tax - , que serán gestionados por el Revenue Scotland (Hacienda de Escocia), creada por la Revenue Scotland and Tax Powers Act 2014, aprobada por el Parlamento escocés el 19 de agosto de 2014 (Royal Assent del 24 de septiembre). Sobre la aplicación de las previsiones de la Scotland Act 2012 en relación con el impuesto más importante (el Impuesto sobre la Renta o Income Tax), vid. Memorandum of Understanding (MoU) on the Scottish Rate of Income Tax. Scottish Government and HM Revenue \& Customs, de 14 de febrero de 2013. 
directa» sobre la independencia y de que el proceso debía realizarse de acuerdo a las normas electorales británicas, bajo la supervisión de la Electoral Commission. Lo demás parecía importar muy poco al Gobierno británico (6).

De acuerdo a lo previsto en el Acuerdo de Edimburgo, se aprobó la Scotland Act 1998 (Modification of Schedule 5) Order 2013, por la que se incorporaba un apartado 5A al mencionado Anexo, permitiendo al Parlamento escocés convocar un referéndum sobre la independencia de Escocia siempre que se realizase antes del fin de 2014, no coincidiese con ningún otro referéndum convocado por el Parlamento británico y la papeleta consistiese en una sola pregunta con dos únicas opciones de respuesta (7). Y, al amparo de la Order, el Parlamento escocés aprobó la Scottish Independence Referendum Act 2013, de 17 de diciembre (Royal Assent), en la que se procedía a la convocatoria del referéndum para el 18 de septiembre de 2014 y se establecía la pregunta, la forma de la papeleta y las disposiciones de funcionamiento y de actuación en el referéndum. Esta ley se

(6) El cálculo del Gobierno británico sobre los efectos de imponer una sola pregunta, directamente sobre la independencia, en un contexto de bajo apoyo a ésta, se demostró pronto, simplista y temerario. Los errores del Gobierno británico los explicitó, más de un año antes del referéndum, Jean Chrétien, antiguo premier canadiense durante la realización del referéndum de Quebec en 1995 y, en consecuencia, con gran experiencia en la materia. De acuerdo a las informaciones aparecidas en la prensa (Financial Times, de 16 de mayo de 2013), en una visita a Londres, invitado por el Gobierno, se mostró muy crítico con la actitud del Gobierno británico, señalando que «estaba poniendo muy fácil a Escocia dejar el RU» y señalando que, entre otras cosas, no debiera haber dejado en manos del Gobierno escocés decidir el momento (timing) del referéndum y, mucho menos, permitir que el resultado fuese válido por mayoría simple, sin exigir ninguna cualificación. De acuerdo con la misma fuente, los altos funcionarios del Gobierno de coalición habrían requerido la opinión de Jean Chrétien sobre las razones por las que se produjo el deslizamiento de votos a favor del «Sí» en el final de la campaña en Quebec, atribuyendo a un alto funcionario la afirmación de que ambas situaciones tenían «paralelismos inquietantes». El desarrollo de los acontecimientos demostraría que, en efecto, así era.

(7) En relación con la pregunta y la papeleta, el Acuerdo de Edimburgo establecía que la pregunta debía ser propuesta por el Gobierno escocés y sometida a la evaluación de la Electoral Commission del RU. El Gobierno escocés propuso la pregunta «Do you agree that Scotland should be an independent country?» —¿Está de acuerdo en que Escocia debería ser un país independiente?»—. La Electoral Commission emitió su Opinion — Referendum on Independence for Scotland. Advice of the Electoral Commission on the proposed referendum question, de enero de 2013 - señalando que, aunque la pregunta era fácilmente comprensible, clara, simple, concisa y directa, se habían puesto de manifiesto problemas acerca de la falta de neutralidad del inicio de la pregunta — «Do you agree...»; «¿Está de acuerdo...?»—, que fue sentida, en general, como favorable y potencialmente impulsora del voto «Sí», aunque ello pueda no haber sido buscado de forma deliberada. Por ello, propuso que la pregunta fuese, simplemente, «Should Scotland be an independent country?». Y ésta fue la pregunta que aceptó, sin objeción, el Gobierno escocés, proponiéndola al Parlamento e incorporándose a la Scottish Independence Referendum Act 2013 一 sección 1(2)-. 
complementa con la Scottish Independence Referendum (Franchise) Act 2013, de 7 de agosto (Royal Assent), en la que se delimita el electorado con derecho a voto en el referéndum, que estará integrado por los mayores de 16 años con derecho a voto en las elecciones al Parlamento escocés y en las elecciones locales - es decir, los residentes en Escocia_-, incluidos los ciudadanos de la Commonwealth, de la República de Irlanda y de la UE (sec. 2) (8).

\section{EL REFERÉNDUM SOBRE LA INDEPENDENCIA DE ESCOCIA}

\section{Los resultados}

Una vez convocado oficialmente el referéndum, se abrió el plazo de inscripción de los electores (9), haciéndolo el 97 por 100 de quienes estaban llamados a votar. Y, finalmente, votó en el referéndum el 84,59 por 100 de los inscritos, lo que representó más de 3.600 .000 votantes. De éstos, el 44,7 por 100 —algo más de 1.600.000 votantes — optó por el «sí» a la independencia, mientras que el 55,3 por 100 — poco más de 2.000 .000 de votantes — optó por el «no» a la independencia. Una diferencia de 10,6 puntos a favor de quienes rechazaban la independencia.

Se puede afirmar que el triunfo del «no» fue claro e inapelable, especialmente si se tiene en cuenta la evolución que habían ido teniendo los sondeos (10) y, muy destacadamente, el realizado por la prestigiosa agencia YouGov, publicado

(8) Suscitó un gran debate el hecho de que no tuvieran derecho de voto los escoceses residentes en otras partes del RU; pero fue el propio Gobierno británico el que, desde su Consultation Paper, había defendido que el derecho de voto se atribuyese a quienes son electores en las elecciones al Parlamento escocés y en las elecciones locales. Otra cuestión polémica, pero tradicional en el RU, es la negación del derecho de voto a las personas cumpliendo penas de prisión: Representation of the People Act 1983, sec. 3 -reformada en 1985-. El TEDH ha dictado varias Sentencias en las que declara que el RU ha violado el art. 3 del Protocolo Adicional núm. 1 del Convenio: vid. las STEDH Hirst (No. 2) v. the United Kingdom, de 6 de octubre de 2005 (Grand Chamber); Greens and M.T. v. the United Kingdom, de 23 de noviembre de 2010; Firth and Others v. the United Kingdom, de 12 de agosto de 2010; McHugh and Others v. the United Kingdom, de 10 de febrero de 2015. Ésta es una de las cuestiones en las que se basa la pretensión del Gobierno conservador de denunciar el CEDH en lo que se refiere a la competencia del TEDH.

(9) Los ciudadanos con derecho a voto deben inscribirse para poder participar efectivamente en el proceso electoral o en el referéndum: Representation of the People Act 1983, sec. 1 -reformada en 2000-

(10) Pueden consultarse los resultados de los diferentes sondeos realizados sobre el referéndum sobre la independencia de Escocia en el sitio web de UKPOLLINREPORT: http://ukpollingreport.co.uk/scottish-independence-referendum. 
doce días antes del referéndum, que preveía el triunfo del «sí»» por un 51 por 100 frente a un 49 por 100 (11). Un sondeo que disparó todas las alarmas, no sólo en el mundo político, sino, muy destacadamente, en el mundo económico, que, hasta entonces, se había mostrado muy confiado y, en consecuencia, poco activo públicamente. Pero los resultados eran alarmantes si se comparan con el respaldo de la opción independentista, por ejemplo, en el momento de aprobarse el Acuerdo de Edimburgo o, incluso, un año antes del referéndum.

¿Qué es lo que llevó el apoyo a la independencia desde el entorno del 30 por 100 al 45 por 100 en el transcurso de un año? Parece que ha habido varios factores, ligados entre sí y amalgamados por la convicción aparentemente mayoritaria de que la independencia no era una opción arriesgada y que podía garantizar un futuro mejor para Escocia. Por una parte, parece haber tenido mucha importancia el fortísimo rechazo a la política de austeridad del Partido Conservador por una gran parte del electorado escocés, en el que el Partido Laborista ha tenido, tradicionalmente, una implantación muy fuerte. A esto se unió, en segundo lugar, el profundo desencanto con el Partido Laborista de una parte muy importante de su electorado tradicional, que se siente desplazado, expulsado del modelo social y económico impulsado por los conservadores y, al mismo tiempo, ajenos o distanciados del nuevo laborismo, en el que no encuentran respuesta adecuada a su situación, por lo que se sienten políticamente desamparados.

Ciertamente, el comportamiento de parte significativa de los tradicionales electores laboristas — que habían seguido votando laborista en las elecciones generales al Parlamento de Westminster, aunque hubiesen empezado a votar crecientemente al SNP en las elecciones al Parlamento escocés - fue determinante en los resultados del referéndum. El campo del «sí» se concentró en convencer a este electorado; y lo logró con una parte significativa. Las encuestas de las semanas previas al referéndum señalaban, reiteradamente, que en torno a un 40 por 100 del electorado tradicional laborista estaba pensando en votar «sí» a la independencia (12).

(11) Vid. los resultados del sondeo de YouGov publicados el 6.09. Los dos últimos sondeos de la misma agencia antes de la votación —el 11 y el 17 de septiembre - otorgaban, finalmente, una ventaja de cuatro puntos a favor del «No» -52 por 100 frente a 48 por 100 , con un 6 por 100 de indecisos.

(12) El diario The Herald, ya el 17 de julio, dos meses antes del referéndum, informando sobre un sondeo de la agencia de investigación de mercados TNS, situaba el apoyo al «Sí» en el 28 por 100 de los electores que habían respaldado al Partido Laborista en las elecciones al Parlamento escocés de 2011 —el nivel electoral más bajo de los laboristas-, mientras que un 20 por 100 de aquéllos estaba indeciso; datos que se insertaban en una tendencia de continuo trasvase de ese electorado — se había incrementado siete puntos en tres meses- 
Vista la orientación que iba tomando el tradicional electorado laborista, en las últimas semanas previas al referéndum el partido empezó a hacer campaña en solitario (13), movilizando todas sus fuerzas y recuperando a figuras como, muy especialmente, al antiguo Prime Minister Gordon Brown, quien consiguió conectar especialmente con parte de ese electorado, aportándole el orgullo y la convicción de que un voto «No» era plenamente compatible con el orgullo de sentirse escocés y con una apuesta decisiva por un mejor futuro para Escocia (14); y, de esta forma, contribuyó, de forma decisiva, al triunfo del «No» y a la magnitud de la victoria, al lograr que parte importante de ese electorado tradicional laborista en crisis no optase, finalmente, por el «Sí» (15).

No cabe duda de que la realización del referéndum sobre la independencia - y todo lo que lo ha rodeado — ha sido el gran instrumento de fortalecimiento del SNP, como partido con expectativas mayoritarias en Escocia (16).

Los resultados del referéndum aportan otro elemento de sumo interés en el contexto escocés: la desigual distribución territorial del apoyo $-\mathrm{y}$ del rechazo- a la independencia. El voto puso de relieve un rechazo muy mayoritario a la independencia en el sur de Escocia, la zona fronteriza con Inglaterra, tanto en los Scottish Borders, en la que se produjo una diferencia de 33 puntos en contra

(13) Aunque la agrupación multipartidista Better Together estaba encabezada por Alistair Darling, destacado miembro del Partido Laborista, miembro de la Cámara de los Comunes (MP) y antiguo Chancellor of the Exchequer durante el gobierno de Gordon Brown, del que salió con un gran prestigio por la forma en que afrontó la crisis financiera, los partidarios de la independencia lograron identificarlo con el sistema de Westminster y, por derivación, con las políticas del Partido Conservador.

(14) Según la mayoría de los analistas, la participación de Gordon Brown en la campaña previa al referéndum fue decisiva en la victoria del «No», hasta el punto de ser identificado en muchos medios de comunicación como, muy probablemente, la persona decisiva en salvar la unión. J. FREEDLAND (2014), adelantó la idea ya antes del verano y se consolidó esa percepción tras sus intervenciones en la última semana de campaña, especialmente tras el rally de Glasgow el día previo a la votación (P. STEPHENS, 2014).

(15) Se estima que, finalmente, entre un 20 por 100 y un 27 por 100 de los votantes tradicionales laboristas votó a favor de la independencia. Sin embargo, Lord Aschroft sostiene que «nearly four in ten of those who voted Labour or Liberal Democrat in the last Westminster elections voted Yes»: vid. la información sobre el sondeo en el sitio web de Lord Ashcroft Polls. Esta diferencia se debe al distinto comportamiento que parte importante del electorado escocés venía teniendo entre las elecciones a Westminster - Parlamento británico — y a Holyrood —Parlamento escocés-.

(16) Las encuestas posteriores al referéndum y las informaciones que se están difundiendo parecen indicar que parte importante de los votantes tradicionales laboristas están engrosando las filas del SNP, que está conociendo un incremento vertiginoso de afiliados. Ya en noviembre de 2014, L. BROOKS (2014), se refería a un incremento de 60.000 nuevos miembros en el SNP. A principios de 2015, M. DICKIE (2015), señalaba que desde el referéndum de septiembre el SNP había cuadruplicado sus miembros, hasta alcanzar los 100.000 . 
de la independencia, como en el distrito de Dumfries \& Galloway en el que la diferencia a favor del «No» casi alcanzó los 32 puntos. En el mismo sentido, el electorado de las islas exteriores, optó mayoritariamente por el rechazo a la independencia con una diferencia de 27 puntos a favor del «No» en las Western Isles o Outer Hebrides - cuya denominación oficial es $\mathrm{Na}$ h-Eileanan Siar, en gaélico escocés - y de entre más de 32 y de 34 puntos, respectivamente, en los otros dos grupos de islas -Orkney y Shetland Islands- Nuevamente, como en su día en Quebec, se ponía en evidencia un problema de posible difícil sostenibilidad de la integridad territorial de una hipotética Escocia independiente o, incluso, de su propia sostenibilidad territorial.

Hay que tener en cuenta que, desde que se puso en marcha el proceso del referéndum sobre la independencia, los Councils de los tres grupos de islas mostraron su oposición a formar parte de una Escocia independiente, reclamando, a través de su manifesto titulado Our Islands, Our Future (17), la posibilidad de pasar a ser posesiones de la Corona, al estilo de las Islas del Canal, o adquirir un estatus similar al de las Islas Feroe, en Dinamarca. Y en sus aguas se concentran las reservas de gas y petróleo de Escocia.

En el análisis de los resultados electorales hay varios elementos adicionales dignos de mención. Por una parte, la significativamente alta proporción de votantes contrarios a la independencia entre las mujeres. Se estima que el voto favorable a la independencia fue entre las mujeres entre diez y quince puntos inferior que entre los hombres (18). Se trata de una tendencia que los sondeos venían mostrando de forma reiterada durante los meses previos al referéndum (Ian Dunt, 2014). En segundo lugar, la edad parece haber tenido un efecto importante en la decantación de la victoria a favor del «No». Parece que sólo en el

(17) En junio de 2013, los representantes de los Councils de los tres grupos de islas hicieron pública una «Declaración conjunta» (Joint Position Statement) bajo el título Our Islands, Our Future, y convocaron una Conference para los días 19 y 20 de septiembre, en los días inmediatamente posteriores al referéndum del 18 , lo que parecía extraordinariamente significativo especialmente en el supuesto de que se hubiese producido una victoria del «Sí». El Gobierno escocés reaccionó inmediatamente, realizando una reunión del Gobierno en las Shetland en julio del mismo año, haciendo pública la Declaración de Lerwick, por la que se procedía a crear el Island Areas Ministerial Working Group; vid. el documento titulado Terms of Reference, de agosto de 2013, así como el titulado Empowering Scotland's Islands Communities, de junio de 2014. Por su parte, el Gobierno británico (Scotland Office) y los tres Councils suscribieron el 15 de agosto de 2014 el documento UK Government and the Three Scottish Islands Councils: A Framework for the Islands.

(18) Sobre la base de los datos obtenidos en el sondeo realizado inmediatamente después del referéndum, Lord Ashcroft (sitio web Lord Ashcroft Polls) afirma: «The results indicate that the No campaign won among men (by a six-point margin) as well as women (by twelve points).» 
grupo de edad entre 25 y 39 años fue mayoritario el voto a favor de la independencia - con una diferencia de unos diez puntos - , mientras que el voto estaba equilibrado en el grupo entre 16 y 24 años, siendo mayoritario el voto contrario a la independencia en los demás grupos de edad, aumentando el porcentaje a medida que se ascendía en el grupo de edad. Algunos análisis sitúan la diferencia a favor del voto «No» en más de treinta puntos en el grupo de mayores de 65 años, grupo en el que pareció influir muy especialmente la incertidumbre sobre el mantenimiento de las pensiones (19). Finalmente, el voto a favor de la independencia ha sido significativamente más alto en las zonas económicamente más deprimidas de Escocia.

\section{Los elementos del debate y las motivaciones del electorado}

El análisis de los resultados adquiere todo su significado en relación con las formas y el contenido de la campaña del referéndum, especialmente durante el año que precedió a la votación.

El Gobierno británico, bajo la dirección del Ministro para Escocia, Michael Moore —que, en octubre de 2013, fue reemplazado por el más «combativo» Alistair Carmichael- , diseñó un programa muy activo de elaboración de un conjunto de informes, sobre las cuestiones más importantes, para tratar de lograr que la decisión del electorado escocés estuviese asentada en una sólida información sobre los beneficios que la Unión había reportado a Escocia, así como las consecuencias negativas, los peligros, que tendría la independencia. Entre febrero de 2013 y junio de 2014 se publicaron, así, quince informes - de los que el último recoge las conclusiones - que integran la serie Scotland Analysis (20) y constituyen el case for the Union. Se trata, ciertamente, de Informes de parte, pero realizados con mucha seriedad, informes de una gran solidez, fundados, en ocasiones, en Informes realizados por académicos de gran prestigio en su respectivo ámbito. El primer Informe, que tuvo un gran impacto, analizaba lo que el sistema de Devolution había supuesto para Escocia, como ejercicio de poder político y, sobre todo, las consecuencias de la independencia de Escocia, especialmente en el ámbito internacional y, muy especialmente,

(19) En este sentido, Lord Ashcroft afirma: «As expected, older voters were the most decisively opposed to independence, with nearly three quarters $(73100)$ of those aged 65 or over voting No.»

(20) Los Informes están accesibles en el sitio web del Gobierno británico: https://www.gov. uk/government/collections/scotland-analysis. 
en relación a la UE (21). Le siguieron otros Informes específicos que fueron analizando, sucesivamente, las cuestiones más significativas que estaban en juego. Entre ellos destacan los relativos a la cuestión de la divisa —esencial en el RU, con gran impacto en el electorado - y de la unión monetaria entre el «RU restante» — se acuñó el acrónimo $r U K$ (remainder $U K$ ) - y la hipotética nueva Escocia independiente; a los servicios financieros y sector bancario - cuestión igualmente esencial en el RU y, muy especialmente, en Escocia-; a la seguridad; a la defensa; a la energía; a la política fiscal; a la investigación científica y técnica - también de gran importancia en el RU y con importante repercusión en Escocia (22) - ; etc. A través de estos Informes, el Gobierno británico, además, hacía pública su posición sobre las cuestiones que tendrían que ser objeto de negociación, para la hipotética independencia de Escocia, en el supuesto de que esa opción recibiese un apoyo mayoritario en el referéndum.

En la múltiple dirección señalada, las cuestiones que centraron el debate público, muy destacadamente, se referían a la cuestión de la permanencia o no en la UE de una Escocia independiente, a la cuestión de la divisa, al sistema financiero y bancario y al sistema de pensiones. En relación con la primera cuestión, el Gobierno británico sostenía que el $r U K$ sería aceptado en la sociedad internacional, con total seguridad, como el Estado sucesor del RU, mientras que Escocia, casi con total seguridad, sería considerado un «nuevo» Estado. Lo que significaría que Escocia, en caso de convertirse en un Estado independiente no se mantendría automáticamente en la UE, sino que tendría que solicitar su adhesión como un nuevo Estado.

Respecto a la divisa, el Gobierno británico rechazó, a través de una declaración formal solemne (statement) el mantenimiento de la unión monetaria entre el $r U K$ y Escocia, en caso de que ésta se convirtiese en un Estado independiente. Las alternativas que ofrecía a una Escocia independiente, en ese supuesto, consistían en que crease su propia divisa - opción que era defendida por algún sector del independentismo, pero que alejaba a una parte significativa del electorado que, potencialmente, podría votar a favor de la independencia-, la adhesión al euro, en caso de incorporación a la UE - cuestión que, especialmente tras la crisis financiera de la eurozona, provoca el rechazo de una parte muy importante de la población británica, incluida la escocesa - o la utilización de la libra esterlina como divisa de hecho, sin unión monetaria — es decir, con el

(21) Esta parte se basaba en el Informe realizado por los Profs. James Crawford (Universidad de Cambridge) y Alan Boyle (Universidad de Edimburgo), que se adjuntó como Anexo.

(22) En este sentido, tuvieron una gran repercusión los manifiestos de importantes grupos de científicos de Escocia, mayoritariamente en contra de la independencia. 
Banco de Inglaterra gobernando la divisa teniendo en cuenta exclusivamente los intereses de la economía del $r U K$, pero no los de la Escocia independiente-; es lo que denominaba la «sterlingization» de la economía escocesa (23).

En lo que se refiere al sector bancario y financiero, el Gobierno británico ponía de relieve el peso absolutamente desproporcionado que ese sector económico tendría en una hipotética Escocia independiente, lo que supondría un riesgo enorme de desestabilización del conjunto de su economía. Hay que tener en cuenta la importancia determinante que el sector financiero tiene en la economía del RU; pero se da la particularidad de que una parte muy importante de las sociedades de ese sector tienen sede en Escocia, por lo que, teniendo en cuenta la pequeña importancia relativa de la economía escocesa en el conjunto del RU, en la hipótesis de que se constituyese como Estado independiente, se produciría una extrema macrocefalia del sector en el conjunto de su economía. De acuerdo con los datos del Gobierno británico, el sector financiero aportó más del 8 por 100 del PIB escocés y emplea alrededor del 7 por 100 de su población laboral. El sector financiero supondría el 1,254 por 100 del PIB de una Escocia independiente, lo que pondría en serio riesgo al conjunto de su economía (24). En este sentido, el Gobierno británico analizaba, comparativamente con la hipotética Escocia independiente, los casos de las crisis financieras y bancarias en Islandia, Chipre, Irlanda, etc., poniendo de relieve los riesgos a los que se enfrentaría una Escocia independiente (25).

Respecto a las pensiones, el Gobierno británico ponía de manifiesto el progresivo incremento de su coste que, por el proceso de envejecimiento de la población, se vería obligada a afrontar una hipotética Escocia independiente en el futuro, lo que crearía problemas para garantizar el mantenimiento de las pensiones públicas (State Pensions) (26).

Éstas fueron las cuestiones de más impacto, en la medida en que afectaban, globalmente, a la propia sostenibilidad de una Escocia independiente, aunque otras cuestiones también tenían un impacto importante, bien desde un punto de

(23) Cfr. Scotland Analysis: Currency and monetary policy (Cm. 8594), de abril de 2013, en págs. 8,9 y otras y, especialmente, análisis en detalle, en cap. 4 , págs. 67 y sigs.

(24) Hay que recordar que en 2008, cuando se produjo la crisis financiera, el Banco de Inglaterra rescató a los dos bancos más grandes de Escocia — que, a su vez, son de los más grandes del RU - con una aportación de 275 mil millones (billions) de libras, lo que sería el equivalente al 211 por 100 del PIB de una Escocia independiente.

(25) Cfr. Scotland Analysis: Financial servicies and banking (Cm. 8630), de mayo de 2013, esp. cap. 1, págs. 15 y sigs.

(26) Cfr. Scotland Analysis: Work and Pensions (Cm. 8849), de abril de 2014, esp. cap. 4, págs. $65 \mathrm{y}$ sigs. 
vista sectorial o territorial, en zonas específicas de Escocia, que se veían más directamente afectadas.

El Gobierno escocés, por su parte, en noviembre de 2013 publicó su White paper titulado Scotland's Future. Your guide to an independent Scotland (27), conteniendo el case for independence y en el que fijaba la fecha de la independencia para el 24 de marzo de 2016, tras 18 meses de negociaciones con el RU y, simultáneamente, con la UE.

Obviamente, el Gobierno escocés dibujaba un panorama fuertemente positivo respecto a la independencia de Escocia. No sólo afirmaba rotundamente la viabilidad de una Escocia independiente — hipótesis que nadie, ni el Gobierno británico ni quienes en Escocia se oponían a la independencia, negaba-, sino que sostenía que, en esa hipótesis, las opciones de Escocia, de su economía, y el bienestar de sus ciudadanos mejorarían de forma muy significativa. La independencia no solamente significaría que el futuro de Escocia estaría en manos de los propios escoceses, sino que permitiría construir un país más próspero y una sociedad más justa, lo que en la actualidad, a juicio del Gobierno escocés, vendría impedido por el «Westminster system» — sistema de Gobierno del RU_- El SNP demostró una gran capacidad para vincular ambas circunstancias y conformarlas como un rechazo al sistema de Westminster, que tuvo una gran recepción entre el electorado escocés (28). Votar a favor de la independencia era la forma más efectiva de mostrar el rechazo a ese sistema de Westminster, que el SNP logró que se identificase crecientemente con las políticas conservadoras y con la incapacidad laborista de dar respuesta a las necesidades de sus antiguos electores. Entre los electores laboristas empezó a calar significativamente la propuesta independentista de un sistema de bienestar a la nórdica (29).

(27) El White Paper del Gobierno escocés, con el case for independence, está accesible en https://www.scotreferendum.com/reports/scotlands-future-your-guide-to-an-independent-scotland/

(28) Es lo que confirmaría el sondeo realizado por Lord Ashcroft inmediatamente después del referéndum, quien afirma: «By far the biggest single driver for Yes voters was "disaffection with Westminster politics". Accordingly, "the principle that all decisions about Scotland should be taken in Scotland' was the most powerful overarching reason for a Yes vote, ahead of the idea that "Scotland's future looked brighter as an independent country" or that "independence would mean no more Conservative governments"»: vid. la información sobre el sondeo en el sitio web de Lord Ashcroft Polls.

(29) Henry McLeish, antiguo First Minister (laborista) de Escocia, expresó esta idea con bastante claridad: lo único que retraía a una parte importante de ese electorado para votar a favor de la independencia eran las serias dudas sobre la fiabilidad de la propuesta del SNP. Se llegó a extender el rumor de que McLeish pensaba votar «Sí»», lo que desmintió rotundamente: vid. el diario The Scotsman, del 22.08.14. El mismo McLeish realizó unas declaraciones a la cadena ITV el 14 de agosto, en las que afirmó: «The Scots need to think carefully before voting "No"». Ya el 6 
La prosperidad económica y la sociedad más justa que el Gobierno escocés consideraba que sería consecuencia de la independencia se asentaba, fundamentalmente, en la potencia de determinados sectores económicos de Escocia, como el sector financiero, el sector energético, la producción de gas y petróleo en el Mar del Norte, la industria de productos alimenticios y de bebidas o la fortaleza de sus sistemas universitario y de investigación. En aras a construir una sociedad más justa en la Escocia independiente, el Gobierno escocés expresaba la intención de crear un fondo soberano, al estilo noruego, con los beneficios obtenidos del gas y del petróleo del Mar del Norte, dirigido a garantizar un sistema de bienestar de estilo nórdico, construyendo una auténtica «Noruega británica», asegurando el bienestar de las generaciones futuras. En el panorama dibujado por el Gobierno escocés, las pensiones - presentes y futuras - no corrían ningún riesgo en una Escocia independiente, que mantendría «lo mejor del actual sistema de pensiones públicas, mejorándolo en lo que sea necesario» (White paper, pág. 140).

Respecto a la divisa, el White Paper defendía el mantenimiento de la unión monetaria con el $r U K$, con la libra esterlina como divisa de la Escocia independiente, lo que, a su juicio, beneficiaba tanto a la Escocia independiente como al resto del RU (30).

Igualmente, a juicio del Gobierno escocés, la Escocia independiente seguiría formando parte de la UE, como Estado-miembro número 29, sin solución de continuidad, sobre la base de lo que denominaba principio de «continuity of effect», sin interrupción de la pertenencia de Escocia a la organización supranacional europea, aunque sin incorporarse a la moneda única - euro-y manteniendo todos las excepciones (opt-outs) reconocidos al RU (31).

El Gobierno escocés no preveía problemas por el peso relativo del sistema financiero en la economía de Escocia; sobre todo veía oportunidades. Tampoco veía problemas en relación con las cuestiones de defensa, ámbito en el que consideraba, por una parte, que la independencia no afectaría a la carga de trabajo

de enero de 2014, en el diario The Scotsman, había defendido la necesidad de un positive case for saying No, que debía ser «made in Scotland» y no «made in London».

(30) El White paper, cit., pág. 7, afirmaba expresamente: «The pound is Scotland's currency just as much as it is the rest of the UK's. The expert Fiscal Commission Working Group concluded that retaining Sterling as part of a formal Sterling Area with the UK would be the best option for an independent Scotland and the rest of the UK.»

(31) Vid. White paper, cit., especialmente págs. 220 y sigs., en el que el Gobierno escocés defendía la aplicabilidad del artículo 48 TUE - reforma interna de los Tratados—, en lugar del artículo 49 TUE —adhesión de nuevos Estados miembros. Sobre la cuestión de la independencia de Escocia y la UE, A. LóPEZ BASAGUREN, 2014b: 69 y sigs. 
de la industria militar, especialmente los astilleros, utilizando, sin embargo, la oposición de una parte importante de la ciudadanía escocesa contra el emplazamiento de los submarinos nucleares británicos (Trident) en aguas escocesas.

Los informes de la serie Scotland Analysis, del Gobierno británico, ciertamente, contenían datos y consideraciones que podían ser discutidos; pero en la base tenían un análisis de la realidad con una sólida apariencia de seriedad, aunque, ciertamente, el panorama que ofrecía de la hipotética independencia de Escocia era fuertemente negativo. El White Paper del Gobierno escocés parecía, por el contrario, dibujar un panorama excesivamente idílico de una Escocia independiente que parecía estar fundamentado en sólidas y firmes convicciones: estaba convencido de que el RU no podría rechazar la unión monetaria; de que la UE no podría rechazar el mantenimiento en su seno de una Escocia independiente; de que el ejército británico seguiría construyendo sus buques de guerra en los astilleros militares escoceses, etc. Unas convicciones que se demostraron extraordinariamente firmes, resistentes a cualquier argumento contrario a ellas y extraordinariamente eficaces.

Los partidarios de la independencia descalificaban las objeciones planteadas a sus previsiones por quienes se oponían a ella, acusándolos de provocar alarmismo (scaremongering) entre el electorado hipotéticamente favorable a la independencia para que desistiese de esa opción (A. Roxburgh, 2014). Los partidarios del mantenimiento de la Unión, por su parte, acusaban a los impulsores de la independencia de estar confundiendo o engañando (misleading) a los electores, al mostrarles un acceso de Escocia a la independencia y una situación como Estado independiente que no se correspondía con la realidad. Una acusación que se refería tanto, al propio significado del referéndum sobre la independencia (32), como a la permanencia de Escocia en la UE, la unión monetaria, las reservas de petróleo (J. McDermott, 2014) o las pensiones, por poner los ejemplos más significativos. En esta confrontación entre la acusación de scaremongering y la de misleading — que llevó a que se denunciase el «secuestro» del debate (N. Walker, 2014a) — en la opinión pública se impuso, muy mayoritariamente, la visión de los defensores de la independencia sobre la falta de credibilidad de unos presagios tan negativos sobre el proceso de conversión de Escocia en un país independiente y sobre la situación de Escocia una vez alcanzada esa condición.

Poco importaba que los partidos de Westminster, por ejemplo, fundamentaran su oposición a la unión monetaria con una Escocia independiente en ar-

(32) Vid., en este sentido, la referencia a la temprana opinión de Vernon Bogdanor en el diario The Telegraph, del 14.05.2011, sobre las implicaciones del referéndum. 
gumentos económicos nada desdeñables: consideraban que la desproporción tanto de población como de la dimensión del sistema económico del $r U K$ y de la Escocia independiente, así como la macrocefalia del sistema financiero de esta última respecto al tamaño de su economía pondría en peligro la estabilidad económica del $r U K$ en el supuesto de crisis en el sistema económico escocés. Para fundamentarlo utilizaban un argumento de mucho impacto en el RU: la crisis de la eurozona habría demostrado que no podía haber una unión monetaria que se pretendiese exitosa si no iba acompañada de unión fiscal, inaceptable para los promotores de la independencia que tenían entre sus objetivos esenciales, precisamente, la independencia fiscal. La mayoría de la opinión pública consideraba que el rechazo a la unión monetaria era una simple amenaza carente de credibilidad si Escocia votase mayoritariamente a favor de la independencia.

Similar suerte corrieron las advertencias de los partidarios del mantenimiento de la unión sobre la inviabilidad del mantenimiento de Escocia en la UE en los términos sostenidos por el Gobierno escocés; especialmente en lo referido a la norma aplicable a su incorporación. Mientras que el Gobierno escocés - e importantes sectores académicos — sostenían que sería de aplicación el proceso de reforma «interna» de los Tratados (art. 48 TUE), el Gobierno británico -y sectores académicos también importantes — sostenían que Escocia debería afrontar un proceso de adhesión como nuevo Estado (art. 49 TUE). Las expresas manifestaciones en favor de esta segunda tesis por parte de importantes representantes de la UE (Presidente del Consejo, Presidente de la Comisión y otros) no debilitaron en lo más mínimo la convicción de los independentistas sobre lo indiscutible de la permanencia, sin solución de continuidad, de Escocia en la UE. Incluso cuando, especialmente, tras el testimonio escrito (written evidence) presentado ante el Parlamento escocés por Jean-Claude Piris (33) —en el que excluía la aplicabilidad del art. 48 TUE y afirmaba la necesaria aplicabilidad del art. 49 TUE_- los más sólidos defensores del procedimiento del artículo 48 TUE consideraron que había que aceptar como prácticamente ineludible el pro-

(33) A petición del European and External Relations Committee del Parlamento escocés, Jean-Claude Piris, antiguo Consejero Jurídico del Consejo Europeo y de la UE y antiguo Director General del Servicio Jurídico del Consejo de la UE, presentó un testimonio escrito — ante la imposibilidad de comparecer personalmente-, con fecha 12.01.2014. Es interesante la lectura del Report on the Scottish Government's proposals for an independent Scotland: membership of the European Union - 2nd Report, 2014 (Session 4), de 23 de mayo de 2014, en el que se recogen las diferentes posturas de quienes comparecieron ante el European and External Relations Committee. 
cedimiento del artículo 49 TUE (34), se transformó en la convicción de que se trataba poco más que de una simple cuestión procedimental que no alteraba el fondo del asunto: el carácter inimaginable de que una Escocia independiente no fuese a mantenerse en la UE, sin solución de continuidad (35).

De la misma forma, la supuesta debilidad de los fundamentos del bienestar a la nórdica no debilitaron la convicción de que ese horizonte fuera plenamente factible para una Escocia independiente. Un bienestar que se asentaba, de forma muy significativa, sobre los beneficios de la explotación del petróleo y gas del Mar del Norte. En este sentido, las objeciones del Gobierno británico a los cálculos - considerados extremadamente optimistas - sobre las reservas de crudo y gas en las aguas escocesas y al precio del petróleo eran descalificadas por el Gobierno escocés como puramente alarmistas (36). El campo del «Sí» fue logrando seducir a una parte muy importante del electorado con el modelo de bienestar de estilo nórdico como modelo de la Escocia independiente, haciendo oídos sordos a las advertencias de que ese modelo exigía un sistema de impuestos radicalmente diferente al existente y al preconizado por el SNP.

En este sentido, la pretensión del Gobierno británico de que los electores escoceses estuviesen adecuadamente informados de lo que suponía la independencia de Escocia parecía saldarse con un importante - y llamativo- fracaso. Por el contrario, el éxito del Gobierno escocés y, en general, de los impulsores de la opción independentista, parecía significativo.

Ciertamente, a la luz de lo que mostraban, con machacona reiteración, los sondeos realizados a lo largo del año que precedió a la votación, la campaña favorable a la independencia pareció convencer a la mayoría de la opinión pública de que los riesgos e incertidumbres de la independencia, sobre los que insistían

(34) Vid. S. TIERNEY y K. BOYLE, 2014, pág. 8, en el que reconocen que el artículo 49 TUE «looks the more plausible route», aunque mantienen que «Article 48 remains a feasible alternative». La convicción sobre la inevitabilidad de la continuidad de una hipotética Escocia independiente en la UE la expresa, igualmente, S. DougLAS-SCOTT, 2014. Sobre la cuestión de la Escocia independiente y la UE vid. J. H. H. WeILER, 2014; J. Murkens, 2014; S. TIERnEy, 2014a; N. WALKER, 2014b, y B. DE WiTTE, 2014.

(35) Cfr. S. TIERNEY y K. BOYLE, 2014: 8, reconocen, en cualquier caso, la inevitabilidad de la ratificación unánime por parte de los Estados-miembro: «Regardless of whether Article 48 or 49 is used, a crucial factor is that the ratification of all Member States will still be needed either for a new accession treaty or for treaty amendments.» Sobre esta cuestión, puede verse A. LÓPEZ BASAGUREN, 2014b: 84 y sigs.

(36) En relación con el precio del petróleo, por ejemplo, las previsiones de los economistas del Gobierno escocés situaban el precio del petróleo en torno a $110 \$$ por barril; hay que tener en cuenta que los precios habían oscilado entre $107 \$$ en agosto de 2013 y $114 \$$ en julio de 2014 . Pero a partir de julio de 2014 el precio del barril empieza a caer, habiendo llegado en febrero de 2015 a menos de $50 \$$ por barril. 
los partidarios del mantenimiento de la unión, tenían carácter alarmista (scaremongering), por lo que no debían ser muy tenidos en cuenta. Sin embargo, parece que la incertidumbre de la independencia y sus riesgos tuvieron un efecto determinante en la clara victoria del «No». El independentismo había logrado un avance enorme entre el electorado, que parecía haberlo colocado al borde de la victoria. Sin embargo, una parte significativa del electorado, finalmente, pareció ser decisivamente afectado por esos argumentos. Parece que ese efecto es difícilmente eludible en una sociedad desarrollada, acomodada, con altos niveles de bienestar, porque un proceso de este tipo lleva inexorablemente aparejada la incertidumbre (S. Tierney, 2014c); y los ciudadanos, la sociedad en su conjunto, ponen mucho en riesgo: su propio nivel de vida. Eso es lo que parece explicar el que el voto favorable a la independencia fuese muy superior en las zonas económicamente más deprimidas de Escocia.

En este sentido, aunque fue muy criticado durante la campaña, parece que quienes se oponían a la independencia acertaron, en última instancia, al focalizar su oposición en los riesgos económicos y en las incertidumbres de la independencia (37); aunque, quizás, eso supuso renunciar a convencer a otro tipo de votantes, con una defensa más positiva del mantenimiento de la Unión.

\section{EL COMPROMISO DE REFORMA DE LA DEVOLUTIONY LAS PROPUESTAS DE LA COMISIÓN SMITH}

En el Acuerdo de Edimburgo, el Gobierno británico impuso su concepción de lo que debía ser un decisive referendum sobre la independencia: un referén-

(37) Sobre la base de los datos obtenidos en el sondeo realizado inmediatamente después del referéndum, Lord Ashcroft afirma: «My questions on the issues that mattered most in people's voting decisions suggest the No campaign was right to focus on the currency and the other uncertainties of independence. More than half (57 100) of No voters said the pound was one of the most important factors in their decision, and the biggest overarching reason for their decision was that "the risks of becoming independent looked too great when it came to things like the currency, EU membership, the economy, jobs and prices" (a more powerful reason for most No voters' decision than "a strong attachment to the UK" or the promise of the best of both worlds with guaranteed extra powers for the Scottish Parliament). Pensions, the NHS and uncertainties about tax and public spending were also mentioned by at least one third of No voters»: vid. la información sobre el sondeo en el sitio web Lord Ashcroft Polls. Hay que tener en cuenta que, en los días previos al referéndum, importantes empresas y bancos manifestaron la posibilidad de trasladar su sede a otras partes del RU si triunfaba la opción favorable a la independencia, informándose, asimismo, de que se había detectado un importante movimiento de traslado de cuentas bancarias a sedes radicadas fuera de Escocia, en otras partes del RU. 
dum con una única pregunta directamente sobre la independencia. Con ello se rechazaba la pretensión del SNP de que el referéndum incluyese, además, una pregunta sobre la ampliación de la autonomía de Escocia, en su objetivo de lograr la devo-max, que parecía ser el auténtico objetivo del partido del Gobierno escocés. La pretensión del Gobierno británico de separar reclamación de independencia y reforma de la Devolution en el referéndum quedó muy pronto desarbolada. A medida que se desarrollaba la campaña, ya muchos meses antes de la fecha de votación, empezó a considerarse que la victoria del «No» estaría ineludiblemente vinculada a la ampliación de la autonomía. Los tres partidos defensores del mantenimiento de la unión, integrados en Better Together, muy pronto empezaron a afirmar que el rechazo de la independencia en el referéndum supondría afrontar inmediatamente la reforma de la Devolution y la ampliación de poderes del Parlamento escocés; y cada uno de los tres partidos opuestos a la independencia realizó su propia propuesta de reforma (38).

Esta vinculación entre voto contrario a la independencia y compromiso de reforma de la autonomía se materializó en la parte final de la campaña, fuertemente impulsada por Gordon Brown, en lo que se denominó el Vow - la «promesa» o el «compromiso»-: los líderes de los tres partidos que propugnaban el «No» en el referéndum —David Cameron, Ed Miliban y Nick Clegg — asumieron el compromiso solemne de que la victoria del «No» iría acompañada de una ampliación de los poderes del Parlamento escocés que sería «faster, safer and better» — «más rápida, más segura y mejor»— que en caso de que triunfara el «Sí» (39). Con ello, se ratificaba solemnemente el fracaso de la estrategia de los partidos de Westminster - especialmente, del Gobierno de coalición y, muy especialmente, del Partido Conservador- (A. Page, 2015, 234; A. McHarg, 2014a) de separar las reclamaciones de independencia y de mayor autonomía, para que el SNP no utilizase los votos favorables a aquélla en reforzamiento de su demanda de devo-max. Con ello se transmitía la impresión de que se ofrecía,

(38) Los Liberal Demócratas escoceses publicaron, en octubre de 2012, el Informe de la Sir Menzies Campbell Commission, titulado Federalism: the best future for Scotland. The Report of the Home Rule and Community Rule Commission of the Scottish Liberal Democrats. Por su parte, los Scottish Labour publican, en marzo de 2014, el Informe titulado Powers for a purpose Strengthening Accountability and Empowering People. Scottish Labour Devolution Commission. Finalmente, los Scottish Conservatives, publican, en mayo de 2014, el Informe de la Commission on the future Governance of Scotland (conocida como Strathclyde Commission).

(39) El Vow se publicó el 16 de septiembre — dos días antes del referéndum - en el Daily Record —el tabloide de más difusión en Escocia—, aunque posteriormente se aclaró que no existía un documento como tal, suscrito por los tres líderes. Sin embargo, no parece que fuese decisivo en la consolidación de la mayoría a favor del «No» (L. BROOKS, 2015; A. TOMKINS, 2014). 
con precipitación y tardíamente, lo que se había negado dos años antes (2012), en la Calman Commission y en la reforma de la Scotland Act que siguió a sus trabajos.

Inmediatamente después de conocidos los resultados del referéndum, en la misma mañana del 19 de septiembre, el Prime Minister David Cameron anunció que Lord Smith of Kelvin —responsable de la exitosa organización de los Commonwealth Games - había aceptado el encargo del Gobierno de «supervisar las conversaciones entre los partidos dirigidas a establecer un paquete de poderes para ser transferidos, de forma que refuercen el Parlamento escocés dentro del RU» (40). De acuerdo con las indicaciones - Terms of reference- establecidas por el Gobierno, Lord Smith tenía que convocar «conversaciones inter-partidarias» (cross-party talks) (41) e impulsar un proceso de «compromiso inclusivo» en Escocia capaz de establecer, antes del 30 de noviembre de 2014, unos «principios de acuerdo» (Heads of Agreement) con recomendaciones relativas a una mayor atribución de poderes al Parlamento escocés; un proceso que debía ser orientado por un Command Paper (Cm.) a publicar antes del 31 de octubre (42) y concluiría con la publicación de los correspondientes borradores (draft clauses) de propuestas legislativas antes del 25 de enero de 2015. Las recomendaciones debían hacer referencia a la atribución de mayores poderes en el ámbito financiero, tributario y del bienestar, fortaleciendo el Parlamento escocés en el seno del Reino Unido.

La Smith Commission trabajó con celeridad e hizo público su informe el 27 de noviembre, cumpliendo el plazo otorgado, con el acuerdo de los cinco partidos que participaron en los trabajos (A. Page, 2015). El Acuerdo de la Comisión Smith sobre la reforma de la Devolution agrupa los principios de acuerdo en tres pilares: (1) proporcionar un acuerdo constitucional duradero pero adaptable

(40) Los documentos pueden consultarse en el sitio web de la Scotland Office del Gobierno británico.

(41) Lord Smith invitó a los cinco partidos presentes en el Parlamento escocés - SNP, Scottish Labour Party, Scottish Liberal Democrats, Scottish Conservatives y Scottish Green Party- a designar dos representantes en la Comisión. La Smith Commission dispone de un sitio web, en el que pueden consultarse, asimismo, los distintos documentos y los trabajos desarrollados por la misma.

(42) Cfr. The Parties' published proposals on further devolution for Scotland, octubre de 2014 (Cm. 8946), basado en las propuestas de reforma de la Devolution presentadas por los tres partidos defensores del mantenimiento de la Unión, citados en nota 46, a los que se añadieron, de cara a los trabajos de la Smith Commission, los documentos presentados por el Gobierno escocés - SNP - titulado More Powers for the Scottish Parliament. Scottish Government Proposals, de octubre de 2014, y por los Scottish Greens — Scottish Green Party submission to Smith Commission on Devolution—, todos ellos accesibles desde el propio Command Paper. 
(responsive) y democrático (43) para el Gobierno de Escocia; (2) ofrecer prosperidad, una economía fuerte (healthy), empleos y justicia social, y (3) fortalecer la responsabilidad financiera del Parlamento escocés.

Entre los «principios de acuerdo» que integran el «primer pilar», destacan algunas cuestiones que son consecuencia de las características peculiares del sistema constitucional británico, como la necesidad de que la legislación del RU establezca el carácter permanente del Parlamento y del Gobierno escocés o la incorporación a la normativa legal de la Sewel Convention (A. López Basaguren, 2014a, págs. 140 y sigs.), junto a cuestiones relativas a la reforma y reforzamiento de las relaciones intergubernamentales, a la participación del Gobierno escocés en la representación del RU en la UE, sobre la gestión del Patrimonio de la Corona (Crown Estate) en Escocia, así como la participación consultiva del Gobierno escocés y el control por parte del Parlamento en determinados ámbitos, como el de los medios de comunicación —reforma de los estatutos de la $B B C$, control parlamentario, nombramientos por la $O F C O M$ (Office of Communication) de los responsables de la $M G$ Alba (el canal en gaélico escocés), etc.- en telecomunicaciones y servicios postales — participación del Parlamento escocés en la determinación por la OFCOM de las prioridades de su actuación en Escocia, etc.- - en transportes - en relación con la actuación de la MCA (Maritime and Coastguard Agency) y de la NLB (Northern Lighthouse Board) - y en energía (regulación del mercado energético y energías renovables) - en relación con las actividades de la OFGEM (Office of Gas and Electricity Markets), la autoridad regulatoria- En este primer pilar se incluyen, además, algunas cuestiones en materia electoral, de menor importancia desde la óptica española, en una perspectiva competencial (44).

(43) En relación con el objetivo de que el acuerdo constitucional sea «durable but responsive», el Informe precisa: «The parties believe that Scotland's devolution settlement should be durable but responsive to the changing needs and aspirations of the people of Scotland within the United Kingdom. As a result, it may be appropriate to devolve further powers beyond those set out in the heads of agreement where doing so would aid the implementation of the consensus reached by the parties in this report» (par. 17, pág. 12) (énfasis añadido).

(44) Entre ellas se incluye la propuesta de una rápida atribución de poderes al Parlamento escocés para que pueda ampliar el derecho de voto (franchise) a los jóvenes entre 16 y 18 años en las próximas elecciones al Parlamento escocés, consolidando, así, la modificación aprobada para el referéndum sobre la independencia. El Gobierno escocés acaba de presentar ante el Parlamento un Proyecto de Ley para la extensión del derecho de voto en los mismos términos para las elecciones al Parlamento escocés y en las elecciones locales: cfr. Scottish Elections (Reducing of Voting Age) Bill [SP Bill 66].

Revista Española de Derecho Constitucional 
En el «segundo pilar», el Informe Smith propone que las pensiones públicas -incluida la single-tier pension (introducida por la Pensions Act 2014) (45), que se implantará a partir de 2016 (aunque inicialmente estaba previsto hacerlo en 2017) - y su regulación normativa se mantenga como una reserved matter (competencia exclusiva) del Parlamento del RU. De la misma forma, el Universal Credit (UC, renta de garantía social, introducido por la Welfare Reform Act 2012) deberá mantenerse como una competencia común, administrada por el DWP (Department for Work and Pensions), aunque se propone que se atribuya al Gobierno escocés la competencia para modificar la frecuencia de los pagos, modificar las previsiones de los pagos de los hogares individuales, así como la capacidad de pagar directamente a los propietarios, modificar los elementos de cálculo del coste de la vivienda en el $U C$ y otros vinculados a él. Sin embargo, la competencia para modificar los demás elementos del $U C$, así como las escalas de reducción de los ingresos (earnings taper) se mantendrán como competencias exclusivas de Westminster, al igual que la configuración de los grupos en que se clasifican los beneficiarios (conditionality groups) (46) y el sistema sancionador. El Informe concluye, en este ámbito, proponiendo la aprobación de Convenios (joint arrangements) entre los Gobiernos del RU y de Escocia, en relación con la supervisión del ejercicio de las funciones por parte del Departamento de Trabajo y Pensiones $(D W P)$ y la gestión del $U C$, similares a los acordados con el HMRC (HM Revenue and Customs, la Hacienda de $\mathrm{Su}$ Majestad) en relación con el tipo escocés del Impuesto sobre la Renta.

Al margen del $U C$, en materia de asistencia social, el Informe propone la atribución a Escocia de competencias en relación con los programas destinados a cuidadores, discapacitados y enfermos (Attendance Allowance, Carer's Allowance, Disability Living Allowance (DLA), Personal Independence Payment (PIP), Industrial Injuries Disablement Allowance y Severe Disablement

(45) La aprobación de la single-tier pension se basó en el documento The single-tier pension: a simple foundation for saving (Cm. 8528), de enero de 2013. Se trata de establecer una pensión de cuantía única (£144 semanales, en términos de 2012-13), para la que se exigirán 35 años de cotización, reduciéndose proporcionalmente la cuantía para aquéllos con un número menor de años cotizados. Sustituye al actual sistema de dos niveles (two-tier system) del basic and additional State Pension.

(46) El UC tiene la finalidad de mejorar los incentivos al empleo y estimular a los demandantes de las ayudas a la obtención de un puesto de trabajo. Por ello, cada beneficiario es ubicado en uno de los grupos de conditionality, de acuerdo a las circunstancias y capacidades de cada uno: a) requisitos no vinculados al empleo; b) requisitos únicamente de entrevista orientada al empleo; c) requisitos de preparación al empleo; d) requisitos vinculados a la obtención de empleo, y, finalmente, e) in-work conditionality, de quienes tienen trabajo pero obtienen ingresos inferiores a los de su umbral de ingresos. 
Allowance); los subsidios que actualmente integran el Regulated Social Fund (Cold Weather Payment, Funeral Payment, Sure Start Maternity Grant y Winter Fuel Payment), así como el Discretionary Housing Payments. Transferencias que deben ir acompañadas de las correspondientes medidas financieras que incorporen a las asignación financiera global del RU a Escocia (block grant, en aplicación de la Barnett Formula) los costes en Escocia de los programas y subsidios mencionados. Sin embargo, el Informe propone que otros programas de subsidios — por defunción, orfandad, maternidad, cuidado infantil, etc. (47) se mantengan como competencias de Westminster (reserved). Pero, el Informe Smith propone el reconocimiento al Parlamento escocés de la competencia para establecer nuevos beneficios sociales o complementos a los que son competencia de Westminster — sin necesidad de autorización del DWP y sin que ello suponga automática reducción de los que se tenga derecho a percibir del sistema común-, a cuyos efectos deberá adaptarse el Benefit Cap —introducido en la Welfare Reform Act 2012, sec. 96- (48) establecido por el Gobierno del RU, con el fin de acoger los beneficios que establezca el Parlamento escocés. Y, de la misma forma, establece que Escocia pueda decidir no aplicar las reducciones que pueda establecer el RU en los beneficios, de forma que pueda superar los techos (top-up) del sistema general.

En el ámbito del empleo, se propone que la determinación del salario mínimo permanezca como una reserved matter, pero se propone la atribución al Parlamento escocés de todos los programas de apoyo a las personas sin empleo. En el área de salud, propone la atribución a Escocia de la competencia sanitaria relativa al aborto, defendiendo la necesidad de considerarlo como una «anómala cuestión de salud»; y considera que debe debatirse el asunto relativo a los xenotrasplantes, la gestación por sustitución (alquiler de úteros), medicamentos, etc., con independencia de lo que se decida sobre su competencia. En transportes, se propone la atribución de competencias en relación con las adjudicación de operadores de ferrocarril, modificación de los límites de velocidad en carretera, señales de tráfico (viarias), así como las competencias desempeñadas por la British Transport Police. En materia de energía, se propone atribuir la competencia sobre el establecimiento de obligaciones en relación con la eficiencia y pobreza energética, así como la concesión de licencias para la extracción de gas

(47) Estos subsidios son: Bereavement Allowance, Bereavement Payment, Child Benefit, Guardian's Allowance, Maternity Allowance, Statutory Maternity Pay, Statutory Sick Pay y Widowed Parent's Allowance.

(48) El Benefit Cap — también conocido como Welfare Cap - supone el establecimiento de un límite en la cuantía máxima de beneficios que una persona o una unidad familiar puede recibir del sistema público de asistencia social.

Revista Española de Derecho Constitucional 
y petróleo en tierra firme - manteniéndose como reserved matter las relativas a la extracción en el mar- Se propone la atribución a Escocia de la competencia en protección y asesoramiento a los consumidores, con especial mención a la capacidad para limitar la proliferación de establecimientos de préstamos a corto plazo sin garantías (Payday Loan shops), así como de los terminales de apuestas con opciones fijas (Fixed-Odds Betting Terminals).

Pero, sin duda, la mayor importancia de la propuesta de reforma de los poderes de Escocia se concentran en el «tercer pilar», referido al reforzamiento de la responsabilidad fiscal del Parlamento escocés. El Informe propone que determinados impuestos se mantengan como competencia del RU: las contribuciones a la Seguridad Social (National Insurance), el impuesto sobre sucesiones (Inheritance Tax) y sobre beneficios de capital (Capital Gains Tax), los Impuestos sobre Sociedades (Corporation Tax) y sobre el suministro de gas, hidrocarburos u otras fuentes de energía (Fuel Duty and Excise Duties).

Nuevamente, las propuestas de reforma se centran, en gran medida, en el Impuesto sobre la Renta (Income Tax). Se propone que siga siendo un impuesto compartido (a shared tax) entre los Parlamentos del RU y de Escocia. Aunque el Parlamento británico mantendrá la competencia para decidir el Presupuesto del RU, incluido el Impuesto sobre la Renta, el Parlamento escocés deberá asumir la competencia para establecer los tipos del impuesto aplicables en Escocia por las rentas procedentes de cualquier fuente, salvo del ahorro (non-savings) y de los dividendos de acciones (non-dividends), así como los umbrales de exención, sin ningún tipo de límites. Todos los demás aspectos del Impuesto sobre la Renta se mantendrán como competencia del RU, incluyendo la aprobación de la annual charge del Impuesto sobre la Renta (49), los ingresos mínimos exentos, la fiscalidad del ahorro y los ingresos por dividendos, la capacidad para introducir y modificar las desgravaciones fiscales y la definición de ingresos. La Comisión propone que la recaudación del Impuesto se siga realizando por la Hacienda del RU (HMRC), en la medida en que el impuesto se aplica sobre una base general en todo el RU, proponiéndose que el Gobierno escocés reembolse al Gobierno británico por el incremento de costes de gestión que suponga la aplicación del

(49) El Income Tax debe ser autorizado legislativamente cada año, lo que el Parlamento del RU realiza a través de la Finance Act, determinando la aplicación del impuesto para el correspondiente ejercicio. Así, p. e., la Finance Act 2014 establece en la sec. 1: «Income tax is charge for the tax year 2014-15». Es una condición legal para poder realizar la exacción del impuesto. Ésa es la decisión que la Comisión Smith propone que se reserve a Westminster; es decir, la decisión de si el impuesto sigue vigente o no para el ejercicio que corresponda. Una vez que la aplicación del impuesto tiene cobertura legal, corresponderá al Parlamento escocés establecer el tipo para todos los ingresos, salvo los procedentes del ahorro y de los dividendos de acciones. 
tipo escocés en relación con las rentas procedentes de non-savings y non-dividends. Los ingresos que el Gobierno escocés reciba por esta vía exigirán una corrección de la asignación financiera global (block grant) del RU a Escocia.

La Comisión Smith propone, asimismo, la atribución a Escocia de los diez primeros puntos del tipo estándar del IVA por las facturas emitidas en Escocia - que deberá delimitarse por medio de negociación entre los dos Gobiernos-, cuyos ingresos deberán suponer un ajuste del block grant. Asimismo, propone la transferencia del Impuesto sobre pasajeros aéreos (Air Passanger Duty), pudiendo introducir libremente otros impuestos que lo reemplacen, debiendo asumir Escocia los gastos que supongan a la Hacienda del RU su eliminación en ese territorio, pero también la transferencia del ahorro que suponga el cese en su gestión. También se propone la transferencia del Impuesto sobre los aglomerados — arena, rocas, etc., extraídos en el RU o importados- (Aggregates Levy).

En el ámbito fiscal una de las cuestiones de mayor importancia propuestas por la Comisión Smith es la relativa a los principios que deben regir las relaciones financieras entre el RU y Escocia, precisadas en el párrafo 95 del Informe. El primer principio es el que establece la necesidad de la cooperación entre ambos Gobiernos para evitar la doble imposición y para establecer una administración tributaria lo más simple posible para los contribuyentes. La atribución de los poderes que se propone deberá estar acompañada de la actualización del marco fiscal de Escocia, coherente (consistent) con el del conjunto del RU. Este marco debe incluir todos los elementos que integran la financiación: presupuesto, planificación, gestión y control de los ingresos y gastos públicos, ajuste del block grant, operaciones de préstamo, gestión de efectivo, reglas fiscales e instituciones fiscales independientes.

La Comisión Smith propone que el marco fiscal incorpore los siguientes criterios: 1) Mantenimiento de la Barnett Formula (A. López Basaguren, 2014) (50), que debe seguir siendo el sistema de determinación de la contribución financiera global (block grant) del RU a Escocia; 2) responsabilidad económica: el nuevo marco deberá garantizar que las consecuencias de las decisiones políticas del Parlamento escocés en relación con la reducción de los ingresos o el incremento de los gastos sea asumida completamente por el presupuesto de Escocia; 3) garantía de que no haya perjuicios por la ampliación de poderes:

(50) Es significativo recordar que el propio Lord Barnett, autor de la «fórmula» cuando era Chief Secretary del Tesoro en el Gobierno (laborista) de James Callaghan, en 1978, clamaba por la reforma de un sistema que fue pensado como solución transitoria y que consideraba como un «terrible error»: vid. entrevista a Lord Barnett en el diario The Telegraph, del 16 de septiembre de 2014.

Revista Española de Derecho Constitucional 
los presupuestos del RU y de Escocia no deben crecer o disminuir simplemente como consecuencia de la transferencia inicial de poderes en materia fiscal y presupuestaria, sino sólo como consecuencia del uso que se haga de ellos, pero deben repercutir directamente las transferencias de nuevas competencias que llevan aparejado gasto; 4) exclusión de perjuicios que deriven de las decisiones tomadas por el RU o Escocia posteriores a las nuevas transferencias de poderes, compensando respectivamente los incrementos o disminuciones de ingresos o gastos que afecten al otro orden de gobierno, de forma que las decisiones sólo afecten a quien las toma; 5) capacidad de endeudamiento: a fin de reflejar los riesgos económicos adicionales, incluida la volatilidad de los ingresos fiscales, el marco financiero debe dotar a Escocia de suficiente capacidad adicional de endeudamiento, de forma que le permita asegurar la estabilidad financiera y dotarla de cautelas que atenúen los riesgos del gasto público en el supuesto de crisis económicas, así como para hacer frente a inversiones de capital, de forma coherente con el marco financiero conjunto del RU y acordados entre los dos Gobiernos; 6) asegurar que el sistema sea factible y sostenible, lo que requerirá revisiones periódicas — para asegurar que sigue siendo fiable, transparente y efectivo- , pero no una continua negociación; 7) control fiscal independiente: el Parlamento escocés deberá prever la extensión y reforzamiento del control independiente de las finanzas públicas, reconociendo la variabilidad e incertidumbre adicional que introduce en el proceso presupuestario la ampliación de ingresos y gastos ejercidos de forma autónoma; 8) turbulencias económicas en el RU: el Gobierno del RU continuará gestionando los riesgos y turbulencias económicas que afecten al conjunto del RU, por lo que el marco financiero deberá garantizar que el Gobierno del RU conserva los instrumentos adecuados para ello, pudiendo, si lo considera necesario para el interés nacional, establecer un impuesto general para el conjunto del RU; 9) puesta en práctica: los Gobiernos del RU y de Escocia deberán trabajar conjuntamente en la Comisión Mixta de Hacienda (Joint Exchequer Committee) para acordar un marco fiscal y financiero reformado para Escocia, de lo que deberán informar periódicamente a los respectivos Parlamentos.

El Informe de la Comisión Smith incluye, finalmente, una serie de cuestiones adicionales para su consideración, que no se concretan en un incremento de las competencias de Escocia, pero que tienen relevancia en el territorio: las relativas a tratar de lograr el reconocimiento del etiquetado «made in Scotland» en el seno de la UE; algunas cuestiones relativas a asilo; la capacidad de permitir la permanencia en Escocia de estudiantes extranjeros que se hayan graduado en su sistema educativo; revisión del sistema vigente de exacción de determinados impuestos (como, por ejemplo, sobre la carne roja o el marisco), de forma 
que Escocia pueda decidir, en cada momento, optar por incorporarse al sistema general del RU, compartiendo, en ese caso, los ingresos obtenidos; tratar de garantizar que las multas, decomisos y sanciones económicas impuestas por los Tribunales escoceses quedan en Escocia, aplicándose los principios de relación fiscal precisados en el párrafo 95 del Informe; sobre revisión de las funciones y funcionamiento de la Dirección de Salud y Seguridad (Health and Safety Executive) en Escocia, considerando la forma en que pueden ser transferidas para servir mejor al pueblo escocés, manteniéndose, sin embargo, en un marco legislativo de salud y seguridad común a todo el RU.

De acuerdo con lo previsto en los Terms of Reference establecidos por el Gobierno británico al constituir la Comisión Smith, en enero de 2015 se hizo público el Command paper conteniendo las Draft Scotland Clauses 2015 (51), destinadas a integrar el Scotland Act Bill o Proyecto de reforma de la Scotland Act.

Se entiende que el desarrollo de las propuestas de la Comisión Smith, a través de la aprobación de las modificaciones legales necesarias, requiere, políticamente, el acuerdo del Parlamento escocés. En este sentido, en octubre de 2014, el Parlamento escocés decidió transformar la Comisión sobre el Referéndum - Referendum (Scotland) Bill Committe - en la Comisión sobre ampliación de la autonomía - Devolution (Further Powers) Committee-, para supervisar el desarrollo del proceso de ampliación de competencias de Escocia, en aplicación de las propuestas de la Comisión Smith. El 14 de mayo, esta Comisión parlamentaria ha publicado un primer informe titulado New Powers for Scotland: An Interim Report on the Smith Commission and the UK Government's Proposals —SP Paper 720, 3rd. Report, Session 4 (2015) —. Se trata de un Informe inicial, que no expresa, en este momento del proceso, la «visión final» de la Comisión sobre la propuesta del Gobierno británico acerca del proyecto legislativo para la aplicación práctica de las propuestas de la Comisión Smith, ni recomendación alguna sobre el consentimiento legislativo por parte del Parlamento escocés (par. 21, pág. 4). Pero la Comisión indica que, a su juicio, las Draft Clauses recogen adecuadamente las propuestas de la Comisión Smith en algunas áreas, pero que hay otras en las que son necesarias mejoras y aclaraciones e, incluso, otras en las que el proyecto legislativo «se queda corto» (par. 7, pág. 2).

Entre las cuestiones que plantea la Comisión del Parlamento escocés encontramos, nuevamente, la dificultad para resolver la cuestión de la garantía del carácter «permanente» del Parlamento escocés — de la autonomía escocesa,

(51) Cfr. Scotland in the United Kingdom: An Enduring Settlement (Cm. 8990), de enero de 2015 .

Revista Española de Derecho Constitucional 
diríamos en España - en un contexto constitucional como el británico. En este sentido, reconociendo ese problema, se propone que se retiren las palabras «se reconoce» - «is recognised»- y que el electorado escocés sea convocado a referéndum en caso de que la permanencia del Parlamento escocés fuese puesta en entredicho. Algo similar ocurre con la incorporación a la legislación (Statutes) de la Sewel Convention. El Committee considera que la Draft Clause no recoge adecuadamente la propuesta de la Comisión Smith, en la medida en que no incorpora el proceso de consulta y consentimiento del Parlamento escocés, pidiendo, además, que se excluya el término «normalmente» que, sin embargo, forma parte de la Convención desde su nacimiento.

El Committee plantea una serie de cuestiones que considera necesario clarificar acerca de los límites establecidos en las Draft Clauses del Gobierno británico sobre la aplicación de la Equality Act de 2006 y de 2010 en relación con la capacidad legislativa escocesa en este campo.

En el ámbito fiscal, el Committee considera que el proyecto del Gobierno recoge adecuadamente las propuestas relativas al Impuesto sobre la Renta (Income Tax), aunque considera que hay cuestiones que necesitan ser clarificadas, como la definición de residencia, de la administración recaudadora, etc., relacionados con la aplicación de los nuevos poderes fiscales atribuidos por la Scotland Act 2012 (par. 164, págs. 43-44), especialmente, la aclaración de la capacidad del Parlamento escocés de establecer un tipo cero en el Impuesto (par. 165, pág. 44). La misma opinión tiene el Committee acerca de las propuestas respecto al IVA (par. 167) y manifiesta su satisfacción respecto a los impuestos Air Passenger Duty y Aggregates Levy (par. 169). La mayor preocupación de la Comisión parlamentaria en este ámbito es la clarificación de la cláusula «no detriment»; es decir, la forma en que se va a entender — y aplicar — la propuesta de que la transferencia de poderes en materia fiscal, por sí misma, no afectará negativamente al block grant - la cuantía financiera global que, en aplicación de la Barnett Formula, recibe Escocia-, sino sólo como consecuencia de la aplicación que Escocia haga de esos poderes (par. 175). Igualmente, muestra su satisfacción con la consideración de que el poder de endeudamiento del Parlamento escocés es muy limitado, aunque considera que no se ha precisado con claridad la forma en que va a funcionar el marco financiero al que se refiere la Comisión Smith, especialmente, en relación con los ciclos económicos expansivos y recesivos, así como la cuestión de la volatilidad (par. 225 y sigs.).

Las objeciones más importantes del Committee se refieren a las cuestiones relativas a la aplicación de las propuestas en el ámbito del bienestar —el segundo gran ámbito al que afectaría la ampliación de poderes-, considerando que el proyecto no recoge adecuadamente las propuestas de la Comisión Smith 
(par. 318 y sigs.); especialmente, en lo que se refiere a la capacidad del Parlamento escocés de crear nuevos beneficiarios, establecer nuevas ayudas, discrecionalmente, crear beneficios complementarios a las ayudas generales (topups), la definición de cuidador, etc. Una objeción con la que, sustancialmente, coincide un destacado miembro de la Comisión Smith, propuesta por el Partido Conservador (A. Tomkins, 2015a). La preocupación del Committee es especialmente significativa en relación con el Universal Credit (UC), las políticas de empleo, etc. Es consciente de que la asunción de los nuevos poderes en el ámbito de la política social dependerá del funcionamiento del sistema de relaciones intergubernamentales que se establezca; considera que ya se han dado algunos pasos, iniciando los trabajos algunas Comisiones conjuntas, pero manifiesta la incertidumbre sobre su desarrollo futuro y propone que su funcionamiento sea objeto de un $\mathrm{MoU}$ - Memorandum of Understanding-.

La Comisión parlamentaria considera, asimismo, de gran importancia garantizar la atribución de la competencia sobre los dos programas de ayudas invernales (los winter fuel y cold weather payments).

Finalmente, hay consideraciones sobre la propuesta relativa al Crown Estate, en cuyo ámbito, reconoce las dificultades para poner en práctica las propuestas de la Comisión Smith, pero manifiesta su disconformidad con el proyecto del Gobierno en las Draft Clauses.

Tras las críticas del Committee del Parlamento escocés, y tras la victoria electoral conservadora del 8 de mayo, el Gobierno británico ha presentado en el Parlamento de Westminster el Scotland Bill — Proyecto de Ley de reforma de la Scotland Act - (52), en las que corrige algunas de las propuestas relativas a las competencias en materia de bienestar, especialmente en relación con la capacidad de introducir ayudas complementarias, superando los límites establecidos en algunas ayudas no directamente relacionadas con el mercado laboral (A. Tomkins, 2015c), en la línea que había reclamado la Comisión parlamentaria escocesa.

En el trámite de enmiendas al Scotland Bill los diputados (MP) del SNP han vuelto a plantear la atribución de la «plena autonomía fiscal» para Escocia, volviendo, así, a sus planteamientos originales y desbordando el acuerdo logrado en la Comisión Smith. El Gobierno británico ha declarado que rechazará las enmiendas del SNP dirigidas a lograr ese objetivo. Con ello, la confrontación política entre el Gobierno escocés y el Gobierno británico vuelve a plantearse

(52) El Scotland Bill, acompañado de las Explanatory Notes, ha sido publicado el 28 de mayo. Está accesible en el sitio web del Parlamento británico (http://www.publications.parliament. uk/pa/bills/cbill/2015-2016/0003/16003.pdf). 
en los mismos términos en que, cuando menos, se viene planteando desde la Comisión Calman y la reforma de la Scotland Act en 2012. En aquellos momentos el SNP fue capaz de convencer a una parte muy importante de la ciudadanía escocesa de la insuficiencia de la ampliación de los poderes fiscales. La cuestión, de cara al futuro, radica en ver si, en esta ocasión, el SNP volverá a ser capaz de expresar adecuadamente la insatisfacción de la sociedad escocesa o, por el contrario, la ampliación de poderes propuesta por la Comisión Smith será capaz de dar satisfacción suficiente a sus demandas.

\section{Conclusiones}

La materialización legal de las propuestas de la Comisión Smith, sobre la base del Scotland Bill, corresponderá al nuevo Parlamento británico que acaba de ser elegido. Cuando todos los observadores consideraban que era inevitable enfrentarse a un Parlamento inestable, sin mayoría de Gobierno - a hung Parliament - (53), el Partido Conservador ha logrado, sorpresivamente, la mayoría absoluta, por una diferencia de 12 escaños, aunque, dada la forma en que se desarrolla la actividad política en la vida parlamentaria británica, sea aventurado afirmar que será suficiente para garantizar al Gobierno una legislatura estable. Por otra parte, el SNP ha obtenido el 50 por 100 de los votos y 56 de los 58 escaños correspondientes a los distritos de Escocia.

El Partido Conservador, inmediatamente después del referéndum escocés, lanzó, formalmente — recogiendo una anterior afirmación de William Hague-, la propuesta English Votes for English Laws (EVEL), como forma de afrontar la vieja West Lothian Question, sobre el problema de la representación (54), incorporándola, finalmente, al programa electoral (The Conservative Party Manifesto 2015, pág. 70). Esta iniciativa, muy criticada en ciertos sectores (V. Bogdanor, 2014; The Guardian, 2015), estaba destinada a tener efectos letales sobre el Partido Laborista, que acaparaba, muy mayoritariamente, la representación

(53) Es expresivo de este sentir general previo a las elecciones, sobre la base de lo que todo tipo de sondeos mostraban de forma reiterada, la afirmación de M. ELLIOT (2015): «One of the few things that can be predicted with any confidence about today's general election is that it will not deliver an overall majority for any single political party.»Vid., sobre la misma cuestión, A. TOMKINS, $2015 \mathrm{~b}$.

(54) El Gobierno de coalición había constituido la Comisión McKay (Cmmission on the Consequences of Devolution for the House of Commons, febrero de 2012) para el estudio de la cuestión. El Informe de la Comisión fue publicado el 25 de marzo de 2013. Sobre este Informe, M. ElLiot, 2013. 
escocesa en Westminster (55) y que fue determinante para lograr la victoria del «No» en el referéndum. En un Parlamento en el que, según se esperaba, los laboristas sólo podrían asumir el Gobierno — en caso de lograr el mayor número de escaños - sobre la base de una importante representación en Escocia y con el apoyo parlamentario del SNP, la propuesta conservadora era una bomba de relojería. En las circunstancias actuales, los Conservadores no tienen —al menos, a corto plazo - la necesidad política inmediata que les llevó a aquella propuesta. Pero han descubierto el rendimiento político de impulsar el nacionalismo inglés, que les permite gobernar el RU desde sus sólidas bases electorales en Inglaterra. Un interés que es ampliamente coincidente con el del SNP respecto a la creciente desconexión de Escocia con el resto del RU. La cuestión a dilucidar reside en la capacidad de lograr un punto de encuentro entre la reclamación nacionalista de plena responsabilidad fiscal de Escocia con los límites que los unionistas conservadores no pueden aceptar traspasar en el camino de Escocia hacia la independencia.

En este sentido, el victorioso David Cameron visitó Edimburgo, el 14 de mayo, inmediatamente después de las elecciones, para entrevistarse con la First Minister escocesa Nicola Sturgeon; tras la reunión declaró a los medios de comunicación su disposición a ir más lejos que lo propuesto por la Comisión Smith en la ampliación de poderes para Escocia (56). Una evidencia más de la sensación de improvisación o de que la evolución de la situación supera continuamente las soluciones propuestas por los partidos de Westminster. Por lo que, como se viene sosteniendo desde hace tiempo (A. McHarg, 2014b), el debate sobre la reforma constitucional del RU no ha hecho más que empezar (57).

Los derroteros que está tomando, en este sentido, la forma de afrontar el asunto escocés por parte de los conservadores británicos trae a la memoria la incapacidad que mostró el unionismo para resolver la cuestión irlandesa a finales del siglo XIX y principios del siglo XX (A. López Basaguren, 2012 y 2015). En aquel momento, el unionismo consideraba que cualquier reforma constitu-

(55) De los 48 escaños perdidos por el Partido Laborista, 40 lo han sido en Escocia, en donde mantiene un solo MP (Member of Parliament). El saldo global del Partido Laborista ha sido de 26 escaños perdidos, dado que ha ganado el escaño en 22 distritos en los que no tenía representación.

(56) Vid. la información aparecida en el diario The Scotsman del 16 de mayo de 2015.

(57) Ya un año antes del referéndum, N. WALKER (2013), en unas reflexiones de gran interés, había mostrado que el proceso en ningún caso terminaría con el referéndum; ni en caso de victoria del «Sí» ni del «No». Sobre la cuestión relativa a lo que hubiese significado una hipotética victoria del «Sí» es extraordinariamente revelador el magnífico análisis de Ch. HÉBERT (2014) sobre la visión que, en esa hipótesis, tenían los protagonistas del referéndum quebequés de 1995. 
cional dirigida a tratar de acomodar Irlanda en el sistema británico de forma suficientemente satisfactoria no era aceptable para Inglaterra, ni serviría para solucionar el problema irlandés (Albert V. Dicey, 1886, 1893 y 1913). La actitud del unionismo conservador puede caer, nuevamente, en parecidos errores a los cometidos en el tratamiento de los proyectos de autogobierno para Irlanda (58), aunque adaptadas a las circunstancias actuales.

Al unionismo conservador no le será suficiente su dominio de Inglaterra, en su desproporcionada dimensión, tanto en población como en peso económico, respecto a Escocia, para impedir una evolución de los acontecimientos que vuelva a plantear la cuestión de la independencia. Las turbulencias que generará el prometido referéndum sobre la permanencia del RU en la UE - especialmente en caso de triunfo de los partidarios de su salida - pueden cambiar, cualitativamente, el statu quo surgido de la derrota en el referéndum de la propuesta de independencia para Escocia; lo que justificaría la reclamación de un nuevo referéndum, que, los partidarios de la independencia afrontarían, inicialmente, en una posición extraordinariamente más favorable que el referéndum de 2014.

\section{BIBLIOGRAFÍA UTILIZADA}

BogdANOR, Vernon (2014): «Why English Votes for English Laws is a kneejerk absurdity», The Guardian, 24.09.

BROOKS, Libby (2014): "Who are the new members of the SNP?», The Guardian, 13.11.

- (2015): «The Vow was not a "decisive factor" in Scotland voting no to independence», The Guardian, 26.03.

CASANAS-ADAM, Elisenda (2014): «Self-Determination and the Use of Referendums: the case of Scotland», Int. J. Pol. Cult. Soc., núm. 27, págs. 47 y sigs.

DE WiTTE, Bruno (2014): «Scotland and the EU: A Comment», UK Constitutional Law Association Blog, 11.09.

DiCEY, Albert V. (1886): England's case against Home Rule, London, John Murray.

- (1893): A Leap in the Dark, London, John Murray.

- (1913): A Fool's Paradise. Being a Constitutionalist's Criticism of the Home Rule Bill of 1912, London, John Murray.

DICKIE, Mure (2015): «Scottish nationalists take delight in Westminster's discomfort», Financial Times, 30.03.

Douglas-SCOTT, Sionaidh (2014): «Why the EU should welcome an independent Scotland», UK Constitutional Law Association Blog, 10.09.

(58) En este sentido, sobre la incapacidad del RU de dar una solución al problema irlandés, es extraordinariamente clarificador, el trabajo de J. KENDLE, 1989. 
DuNT, Ian (2014): «Why are women so againts Scottish independence?», web politics. co.uk, 13.08 .

ELLIOT, Mark (2013): «Devolution, the West Lothian Question, and the nature of constitutional reform in the United Kingdom», UK Constitutional Law Association Blog, 26.03 .

— (2015): «Hung Parliaments: some election-night reading», blog Public Law for Everyone, 7.05 .

Esteban CAMPos, Carlos G. (2005): Devolution y forma de gobierno en Escocia, Madrid, CEPC.

FreEdLAND, Johathan (2014): «Gordon Brown is back, and may be the man to save union», The Guardian, 17.06.

GuARDIAN, The (2015): «The Guardian view on English Votes for English Laws: playing with fire», The Guardian, 3.02.

HÉBERT, Chantal — with Jean Lapierre - (2014): The morning after. The 1995 Quebec referendum and the day that almost was, Alfred A. Knopf.

KENDLE, John (1989): Ireland and the Federal Solution. The debate over the United Kingdom Constitution, 1870-1921, Kingston/Montreal: McGill-Queen's University Press.

LÓPEZ BASAGUREN, Alberto (2012): «Reforma del Estado autonómico e inclusión de los nacionalismos: un reto», Seminario Debates sobre el estado autonómico. Desafios actuales y futuros (Altea, Alicante). Disponible en: http://www.fundacionmgimenezabad.es/index.php?option $=$ com_content\&view $=$ frontpage\&Itemid $=100660$.

- (2014a): «Devolution: Desarrollo y perspectivas de la autonomía territorial en el Reino Unido», en Juan J. SOlOzÁBAL (ed.): La reforma federal. España y sus siete espejos, Madrid: Biblioteca Nueva, págs. 123-157.

- (2014b): «La independencia de Escocia en la Unión Europea. Los efectos de la secesión de territorios en la UE entre Política y Derecho», Teoría y Realidad Constitucional, núm. 33, págs. 9-97.

- (2015): «Sobre el desarrollo federal del sistema autonómico», en BALAGUER CALLEJón, Francisco; García Herrera, Miguel A.; Asensi SABATER, José (eds.): Liber Amicorum en honor de Carlos de Cabo Martín, Valencia: Tirant lo Blanch, 2015 (en prensa).

MCDERMOTT, John (2014): «Scottish Government is misleading Scots about oil», Financial Times, 13.07 .

McHARG, Aileen (2014a): «The Vow: Vote for More Devo», Scottish Constitutional Futures Forum, 17.09.

- (2014b): «What does the Union need to do to survive?», UK Constitutional Law Association Blog, 26.09.

Murkens, Jo E. (2002) —with Peter Jones and Michael Keating —: Scottish Independence. A Practical Guide, Edinburgh: Edinburgh University Press.

- (2014): «Scotland and the EU: A Comment», UK Constitutional Law Association Blog, 10.09 .

Revista Española de Derecho Constitucional 
PAGE, Alan (2015): «The Smith Commission and Further Powers for the Scottish Parliament», Edinburgh Law Review, núm. 19, págs. 234-239.

RoXBURGH, Angus (2014): «With seven months to go to the Scottish referendum, the scaremongering has begun», The Guardian, 18.02 .

SÁNCHEZ FERRO, Susana (2015): «El referéndum de independencia escocés: ¿evolución o revolución del sistema constitucional británico?», REDC, núm. 103, págs. 111156.

STEPHENS, Philip (2014): «A reborn Gordon Brown could be the man who saved the union», Financial Times, 18.09.

TIERnEY, Stephen, y BoYLE, Katye (2014): «An Independent Scotland: The Road to Membership of the European Union», Scottish Centre on Constitutional Change, Briefing Paper, 20.08.

- (2014a): «Scotland and the EU: A Comment», UK Constitutional Law Association Blog, 11.09 .

- (2014b): «Why is Scottish independence unclear?», UK Constitutional Law Association Blog, 25.02.

TOMKINS, Adam (2014): «Reflexions on 2014», blog Notes from North Britain. On Law, Politics and the British Constitution, 26.11.

Tomkins, Adam (2015a): «Welfare jigsaw is hard, but pieces must fit», The Times, 26.01.

- (2015b): «A Fixed-Term Hung Parliament?», blog Notes from North Britain. On Law, Politics and the British Constitution, 04.05.

- (2015c): «The Smith Commission Agreement and the Scotland Bill», blog Notes from North Britain. On Law, Politics and the British Constitution, 28.05.

WALKER, Neil (2013): «The receding tape», UK Constitutional Law Association Blog, 22.09 .

- (2014a): «Hijacking the Debate», UK Constitutional Law Association Blog, 18.02.

- (2014b): «Scotland and the EU: A Comment», UK Constitutional Law Association Blog, 11.09 .

WeILER, Joseph H. H. (2014): «Scotland and the EU: A Comment», UK Constitutional Law Association Blog, 10.09 . 
